Glasser states, "We can also hope serious readers and scholars dip into the muck from time to time and bring to our attention neglected gems." "Muck"? Muck is a synonym for crap. But, in the present fiction market, muck connotes an elite spa mud bath. Philip Roth, for example, is publishing an alternative-history novel, The Plot against America. When a new Roth novel is ensconced in science fiction subgeneric muck-crap, there is only one collective exclamation for elitist, textist critics: oy!

I say: enough already with the antiquated emphasis on genre. Enough already with dullness, textism, and elitism.

Marleen S. Barr Montclair State University

PS. Regarding Glasser's remark that "Marleen S. Barr may want to turn her phaser down from kill to stun, or at least point it in the right direction": as an extraterrestrial, I emphasize that the phaser setting and direction Marleen S. Barr chooses are right on target. At the last meeting of the Interplanetary Feminist Science Fiction Scholars Convention, Barr reported that a recent experience with the MLA Publications Committee suggests that textism is alive and well in some academic circles. Phasers are still sciencefictional on Earth; the force was with the MLA committee-and it killed a science fiction critical anthology dead. I told Barr that I could get her a phaser wholesale here on Mars. She declined. She says that she is a pacifist who, remaining unphased, wishes to fight fire with fire by speaking truth to textism.

Shulamyth Squidsky

Mars Equatorial University Gusev Crater Underwater Branch

Reply:

I appreciate the comments by Perry Glasser and by Julia Douthwaite.

Carl Freedman Louisiana State University, Baton Rouge

\section{Science in Gattaca}

\section{TO THE EDITOR:}

The broader argument of Eric S. Rabkin's "Science Fiction and the Future of Criticism" (119 [2004]:
457-73) - that science fiction partakes in, as well as activates, a larger cultural system-is helpful and persuasive. The photographs in his essay implicate the United States of the 1950s in the same industrial model that its popular culture exaggerated-through science fiction-and projected onto the communist, "mindless" other. Charlie Chaplin's Modern Times, set in the years of the American Depression, had already satirized the mechanical worker-man a decade earlier, thereby participating, as Rabkin rightly suggests, "in the cultural system of science fiction" (465).

"Science fiction was born in part out of distrust of science," writes Rabkin, "a distrust it continues to manifest in works like Gattaca, but it also bolsters a faith" (472). My point of contention lies in this proposition that Gattaca is a (genuine) manifestation of a distrust in science. Unlike Chaplin's film, in which the machine "threaten[s] to turn us into generalized pulp" (465), Gattaca puts its trust (and ours) in the heroic efforts of its protagonist, whose personal ambition is to become an astronaut. The "paraplegic's struggle to climb the double helix," as Rabkin sees it, can be read as heroism only in a serious attempt to go against the film's sly, ideological grain. For the movie aligns science with the kind of self-serving individualism that in the end leaves everything intact: the protagonist receives subversive help in fighting an unjust system (from the paraplegic and other supporting characters) but gives nothing in return, so that we may celebrate his final escape from the earthly eugenicist dystopia to a faraway planet as the achievement of his own (American) dream. And the paraplegic conveniently offs himself at the end of the film because once he has served his purpose-providing his genetically superior identity to the genetically inferior hero-there is no longer a place for him on earth. And yet he is the really physically handicapped character. The distrust of science that the narrative stipulates-in suggesting that genetic predisposition, in the wrong hands, constitutes a mismeasure of man, to use Stephen Jay Gould's argument and phrasing - is effectively annihilated by the mythos of the individual that in the $1950 \mathrm{~s}$ already clouded any widespread recognition of Levittown as a depressing ant farm. If there's distrust here, it's secret, voiceless, an insider joke. Science fiction, too, warrants a certain distrust, I think.

Angela Flury DePauw University 